\title{
Teks Mitos Ida Ki Dukuh Sakti di Pura Gelar Desa Pakraman Gelogor Kecamatan Ubud Kabupaten Gianyar Analisis: Struktur, Fungsi, dan Nilai
}

\author{
Kadek Adidi Saputra $^{1^{*}}$, Ni Made Suryati ${ }^{2}$, Tjok Istri Agung Mulyawati ${ }^{3}$ \\ ${ }^{[123]}$ Prodi Sastra Bali Fakultas Ilmu Budaya Universitas Udayana \\ ${ }^{1}$ [adidisaputra2002@gmail.com] [2 [suryati.jirnaya@yahoo.com] \\ 3 [tiamulya59@gmail.com] \\ *Coressponding Author
}

\begin{abstract}
Abstrak
Penelitian ini berjudul "Teks Mitos Ida Ki Dukuh Sakti di Pura Gelar Desa Pakraman Gelogor, Kecamatan Ubud, Kabupaten Gianyar; Analisis Struktur, Fungsi, dan Nilai. Kajian ini bertujuan untuk mendeskripsikan struktur isi yang terdapat dalam teks mitos Ida Ki Dukuh Sakti serta menganalisis fungsi dan nilai. Teori yang digunakan adalah teori struktural, teori fungsi, dan teori nilai. Tahap penyediaan data digunakan metode simak dan teknik catat. Digunakan metode wawancara dibantu dengan teknik rekam dan teknik catat. Pada tahap penyajian analisis data, digunakan metode informal. Struktur isi yang membangun teks mitos Ida Ki Dukuh Sakti ada tiga, yaitu pembukaan, isi, dan penutup. Pada bagian pembukaan menjelaskan mengenai sosok Ida Ki Dukuh Sakti. Pada bagian isi menjelaskan tentang upacara, sraddha sebagai wujud bhakti, dan musibah yang terjadi di Desa Pakraman Gelogor. Pada bagian penutup menjelaskan tentang akhir dari teks mitos Ida Ki Dukuh Sakti. Fungsi yang terkandung dalam teks mitos Ida Ki Dukuh Sakti, yaitu (1) fungsi sosial, (2) fungsi sebagai keharmonisan unsur alam, dan (3) fungsi religius; sedangkan nilai yang terkandung dalam teks mitos Ida Ki Dukuh Sakti adalah (1) nilai magis dan (2) nilai kearifan lokal.
\end{abstract}

Kata Kunci: mitos, struktur, fungsi, nilai

\begin{abstract}
The study is titled "The Text of Myth Ida Ki Dukuh Sakti in Gelar temple Pakraman Gelogor village, Ubud District, Gianyar Regency; Analysis of Structure, Function, and Value". This study aims to describe the structure of the content contained in the mythical text of Ida Ki Dukuh Sakti and to analyze the function and value. The theory used in this research is structural theory, function theory, and value theory. Phase of data provision used method of recall and technique of record. It also used interview method assisted by recording technique and record technique. In the data analysis presentation stage, informal methods are used. The content structure that built the mythical text of Ida Ki Dukuh Sakti there are three, namely opening, content, and cover. In the opening section describes the figure of Ida Ki Dukuh Sakti. In the contents describe the ceremony, sraddha as a form of bhakti, and the disaster that occurred in the village of Pakraman Gelogor. In the closing section describes the end of the mythical text of Ida Ki Dukuh Sakti. The functions contained in the mythical text of Ida Ki Dukuh Sakti, namely (1) social function, (2) function as harmony of natural element, and (3) religious function; while the values contained in the mythical text of Ida Ki Dukuh Sakti are (1) magical values and (2) the value of local wisdom.
\end{abstract}

Keywords: myth, structure, function, value 


\section{Pendahuluan}

Sastra lisan merupakan karya sastra dalam bentuk ujaran (lisan). Bentuk dari sastra lisan itu sendiri dapat berupa prosa (seperti mite, dongeng, dan legenda). Fungsi dari sastra lisan sendiri tidak hanya sekedar untuk kebutuhan seni melainkan terdapat pula unsur pendidikan yang hendak disampaikan di dalamnya, seperti nilai moral dan nilai agama dalam masyarakat (Hutomo, 1991: 21). Dimana dalam menganalisis penelitian ini penulis mengambil salah satu sastra lisan yaitu mitos. Menurut Ghazali (2011: 114-125), mitos adalah cerita atau kisah para dewa, asal-usul suatu tempat, alat, bangsa, dan hal-hal yang berkaitan dengan kekuatan gaib beserta hal-hal ajaib. Mitos membentuk suatu pengetahuan esoteris yang mengandung kekuatan religius magis. Bila orang mengetahui asal-usul obyek, seperti binatang, tumbuh-tumbuhan dan sebagainya, berarti dia memperoleh kekuatan magis terhadap obyek-obyek tadi sehingga ia dapat menguasai, memperbaiki, atau mereproduksikannya menurut yang dikehendakinya. Dalam hal ini peneliti menggunakan objek mitos yang berjudul teks mitos Ida Ki Dukuh Sakti di Pura Gelar Desa Pakraman Gelogor.

Mitos ini memiliki keunikan tersendiri, karena mitos Ida Ki Dukuh Sakti merupakan cikal bakal dari segala upacara yajna yang dilakukan di Pura Gelar, dengan segala ritual yang dilakukan. Masyarakat meyakini jika hendak melaksanakan upacara yajna seperti ngaben, potong gigi, pernikahan, maupun kegiatan yang bersifat melibatkan khalayak banyak, masyarakat selalu menghaturkan banten upakara ke hadapan Ida Ki Dukuh Sakti yang dilaksanakan di Pura Gelar dan diaturkan oleh Jero mangku Jigra agar kegiatan yang dilakukan oleh masyarakat berjalan dengan lancar (labda karya). Setiap 6 bulan sekali masyarakat Desa Pakraman Gelogor selalu melaksanakan upacara piodalan di Pura Gelar yaitu pada Buda Kliwon Pahang. Selain tempat memohon keselamatan dan pengrastiti jagat, banyaknya masyarakat yang meminta permohonan taksu. Simbolis dari mitos Ida Ki Dukuh Sakti berupa bangunan pelinggih rong telu, yang berada di barat laut di wilayah Desa Pekraman Gelogor.

\section{Pokok Permasalahan}

Berdasarkan latar belakang di atas dirumuskan masalah sebagai berikut.

1. Bagaimanakah struktur teks mitos Ida Ki Dukuh Sakti di Pura Gelar Desa Pakraman Gelogor, Kecamatan Ubud, Kabupaten Gianyar?

2. Bagaimanakah fungsi teks mitos Ida Ki Dukuh Sakti di Pura Gelar Desa Pakraman Gelogor, Kecamatan Ubud, Kabupaten Gianyar?

3. Nilai apakah yang terkandung pada teks mitos Ida Ki Dukuh Sakti di Pura Gelar Desa Pakraman Gelogor, Kecamatan Ubud, Kabupaten Gianyar?

\section{Tujuan Penelitian}

Tujuan merupakan sesuatu yang ingin dicapai dan perlu dijelaskan agar arahan penelitian dapat mencapai sasaran yang diharapkan (Triyono, 1994: 35).Tujuan penelitian dibagi menjadi dua, yaitu tujuan umun dan tujuan khusus.

\section{a. Tujuan Umum}

Tujuan umum penelitian ini adalah untuk memperoleh pengetahuan dan pemahaman yang lebih mendalam mengenai keberadaan teks Mitos Ida Ki Dukuh Sakti yang berada di Pura Gelar Desa Pakraman Gelogor, Kecamatan Ubud, Kabupaten Gianyar. Penelitian ini juga bertujuan untuk membangkitkan 
semangat masyarakat agar turut menjaga dan melestarikan kebudayaan Bali yang diwariskan oleh nenek moyang pada zaman dahulu yang digunakan sebagai identitas daerah dan memperkaya khasanah budaya bangsa.

\section{b. Tujuan Khusus}

1. Untuk mendeskripsikan struktur teks mitos di Desa Pakraman Gelogor.

2. Untuk mendeskripsikan fungsi teks mitos di Desa Pakraman Gelogor.

3. Untuk mendeskripsikan nilai-nilai yang terkandung pada teks mitos di Desa Pakraman Gelogor.

\section{Metode Penelitian}

\section{a. Metode dan Teknik Penyediaan Data}

Metode yang digunakan dalam penelitian ini adalah metode observasi. Metode observasi adalah memperoleh data atau informasi secara langsung di lapangan. Kemudian teknik yang digunakan adalah teknik wawancara, teknik rekam dan teknik penerjemah. Teknik wawancara adalah teknik tanya jawab kepada narasumber selaku informan yang mengetahui objek penelitian ini, teknik rekam dan teknik catat dengan merekam langsung apa yang disampaikan narasumber dan teknik penerjemah agar bahasa yang digunakan sesuai dengan bentuk bahasa sasaran yang wajar.

\section{b. Metode dan Teknik Analisis Data}

Metode yang digunakan adalah metode kualitatif. Metode kualitatif ini memberikan perhatian terhadap data ilmiah, data dalam hubungannya dengan konteks keberadaannya (Ratna, 2009: 47). Metode kualitatif lebih menekankan pada aspek pemahaman secara mendalam terhadap suatu masalah daripada melihat permasalahan untuk penelitian generelisasi dengan memakai teknik penerjemahan.

\section{c. Metode dan Teknik Penyajian Hasil Analisis Data}

Metode yang digunakan adalah metode informal. Metode informal digunakan untuk menyajikan hasil analisis data dengan kata-kata atau kalimat biasa dalam bahasa Indonesia. Teknik yang digunakan pada tahap ini dengan cara berpikir deduktif dan induktif.

\section{Pembahasan}

\section{Struktur Isi Teks Mitos Ida Ki Dukuh Sakti di Pura Gelar Desa Pakraman Gelogor}

Analisis struktur dari teks mitos Ida Ki Dukuh Sakti ini meliputi unsurunsur yang membentuk teks mitos Ida Ki Dukuh Sakti yaitu bagian pembukaan, isi, dan penutup.

\section{1) Pembukaan}

Pembukaan berarti permulaan yang mengantarkan karya sastra dan yang merupakan bagian sastra tersebut (Sudjiman, 1984: 60). Teks mitos Ida Ki Dukuh Sakti ini memiliki bagian pembukaan berupa ulasan sosok Ida Ki Dukuh Sakti yang berada di Desa Pakraman Gelogor dan mengawali cerita tersebut menuju bagian isi. Bagian pembukaan pada teks mitos Ida Ki Dukuh Sakti terdapat pada kutipan berikut ini.

"Kacerita di masa dumunan wènten pendeta sakti mewasta Ida Ki Dukuh Sakti. Perawakan beliau madué angga sane ageng, mebulu putih, mejéngot putih lan nganggén wastra makancut dawa lan makta tungked dawa. Ida Ki Dukuh Sakti puniki mapangawak lingsir lan sakti, Ida Ki Dukuh Sakti dados pemimpin krama wong samar sane megenah ring wewidangan Desa Pakraman Gelogor. Ida melinggih lan ka sungsung ring Pura 
Gelar sané megenah ring kaja kauh wewidangan Desa Pakraman Gelogor." Terjemahan:

"Diceritakan pada jaman dahulu ada seorang pendeta sakti yang bernama Ida Ki Dukuh Sakti. Perwujudan beliau adalah bertubuh sangat besar, berjenggot putih, badannya berbulu dan berwarna putih serta mengenakan kamen yang berkancut panjang dan membawa tongkat panjang. Ida Ki Dukuh Sakti merupakan seorang kakek tua dan sakti yang berstatus sebagai pemimpin dari krama wong samar yang berada di dekat Pura Gelar. Beliau bersemayam dan dipuja di Pura Gelar yang terletak di bagian barat laut Desa Pakraman Gelogor."

Dari kutipan tersebut merupakan sebuah ulasan singkat tentang pembukaan dari teks mitos Ida Ki Dukuh Sakti. Adapun hal-hal yang terdapat di dalamnya adalah perkenalan tokoh, penggambaran perawakan tokoh, dan tempat pemujaan beliau. Bagian pembukaan teks mitos Ida Ki Dukuh Sakti ini berisikan tentang pengenalan tokoh utama serta kepercayaankepercayaan masyarakat setempat tentang keberadaan tokoh utama yang terdapat di Desa Pakraman Gelogor.

\section{2) Isi}

Isi memiliki pengertian yaitu sesuatu yang ada, termuat, terkandung dalam sesuatu, apa yang tertulis didalamnya, inti atau bagian pokok dari sesuatu (KBBI, 1999: 388). Berdasarkan pengertian tersebut bagian isi ini merupakan bagian pokok atau inti dari teks mitos Ida Ki Dukuh Sakti. Bagian isi dibangun oleh unsur-unsur yang menjadikan bagian ini menjadi pokok atau inti. Adapun unsur yang membangun bagian isi ini adalah upacara, sradha dan musibah yang terjadi di Desa Pakraman Gelogor.

\section{(1) Upacara}

Arwati (2010: 83) menyatakan upacara adalah salah satu kerangka dari agama Hindu. Agama Hindu mempunyai tiga kerangka, yaitu tatwa, susila, dan upacara. Upacara merupakan lapisan paling luar atau kulit dari agama Hindu, yang bertujuan untuk mendekatkan diri ke hadapan Tuhan dan manifestasinya, dengan sutau tujuan tertentu. Upacara piodalan termasuk dalam upacara keagamaan Dewa Yajna, yaitu bermakna korban atau persembahan suci tulus ikhlas sebagai rasa bhakti kepada Ida Sang Hyang Widhi Wasa dan segala manifestasi beliau. Pelaksanaan upacara piodalan di Pura Gelar dilaksanakan setiap enam bulan sekali. Hal tersebut menunjukan rasa bhakti masyarakat kepada beliau Ida Ki Dukuh Sakti yang bersemayam di Pura Gelar.

Dalam melaksanakan upacara yajna tidak lepas dari adanya unsur mantra. Suhardana, (2008: 273) menyatakan kata mantra berasal dari bahasa Sansakerta yaitu manana yang disingkat man 'pemikiran, perencanaan, perenungan, pertimbangan, pernyataan rasa hormat' dan dari trana 'perlindungan dan pertolongan'. Mantra dapat diartikan sebagai pernyataan rasa hormat kepada Tuhan untuk memohon keselamatan dan perlindungan Beliau. Mantra merupakan unsur utama dalam upacara agama Hindu. Mantra yang digunakan oleh pemangku di Pura Gelar dapat dilihat pada kutipan berikut.

“...Ratu Ida Ki Dukuh Sakti sane melinggih deriki, titiang ngaturang sesaji miwah santun, daksina, banten suci lan sarwa wohwohan sane katuran ring Iratu, mangde sueca ngamicayang kerahayuan ring kramane sami ring jagat Gelogor."

Terjemahan :

"..Ratu Ida Ki Dukuh Sakti yang melinggih di sini, saya menghaturkan sesaji dan santun, daksina, banten suci 
dan jenis buah-buahan yang dihaturkan untuk Iratu, semoga sueca memberikan keselamatan bagi seluruh masyarakat di jagat Gelogor."

Dari kutipan di atas dapat dilihat bahwa mantra adalah sarana untuk memohon keselamatan kepada Tuhan dan manifestasi-Nya. Mantra dalam kutipan di atas berfungsi sebagai alat komunikasi kepada dewa-dewa maupun niskala. Hal tersebut diyakini oleh Desa Pakraman Gelogor jika hendak melaksanakan kegiatan keagamaan selalu memohon restu yang ditunjukan kepada Ida Ki Dukuh Sakti yang berstana di Pura Gelar dengan menghaturkan banten pakeling agar kegiatan upacara keagamaan yang dilaksanakan oleh masyarakat dapat berjalan dengan lancar.

\section{(2) Sraddha Sebagai Wujud Bhakti}

Kata sraddha atau kepercayaan /keyakinan sangat penting dalam kehidupan ini, dari sraddha memiliki pengaruh yang kuat dalam berprilaku. Secara etimologis kata sradhha (yang kata asli dari Bahasa Sanskerta 'śraddha') berasal dari śrat berarti sebuah akar kata benda yang mungkin berarti 'hati' dan akar kata $d h \bar{a}$ yang berarti menempatkan; dengan demikian akan berarti : 'menempatkan hati seseorang pada sesuatu'. Dari pemaparan tentang pengertian sraddha, dapat disimpulkan bahwa dalam kajian teks mitos Ida Ki Dukuh Sakti lebih cenderung pada keyakinan terhadap adanya kekuasaan Tuhan atau Brahman dalam hal ini beliau digambarkan sebagai pendeta Ida Ki Dukuh Sakti. Beliau dipercaya eksistensinya dan sangat dipuja oleh masyarakat di Desa Pakraman Gelogor. Keberadaan beliau sangat penting kaitannya dengan keberadaan dengan Desa Pakraman Gelogor sampai saat ini. Beliau dianggap sebagai pelindung niskala bagi masyarakat di sana setiap hal dan kegiatan yang dilaksanakan di masyarakat dapat berlangsung atas berkat beliau hal tersebut dapat dilihat dalam kutipan teks mitos Ida Ki Dukuh Sakti berikut ini.

“...ritatkala para krama wénten sané madué kekarya ring Desa Pakraman Gelogor, sekadi wénten masangih, ngantén, ngabén, karya ring Pura lan sané tiosan. Krama sané medué kekarya makta bantén ngaturang Jero Mangku nunas ring Ida Ki Dukuh Sakti mangda ngicén keselamatan lan kerahayuan ring krama Desa Pakraman Gelogor." Terjemahan :

“...ketika masyarakat hendak melakukan kegiatan baik di bidang keagamaan (yajna) seperti potong gigi, ngabèn, pernikahan maupun kegiatan yang bersifat melibatkan khalayak banyak. Masyarakat yang melaksanakan kegiatan upacara yajna, maka harus membawa dan menghaturkan banten melalui Jero Mangku agar Ida Ki Dukuh Sakti memberkati keselamatan dan kedamaian kepada masyarakat Desa Pakraman Gelogor."

Dari pemaparan kutipan tersebut menunjukan bahwa kepercayaan masyarakat di Desa Pakraman Gelogor sangat tinggi terhadap keberadaan Ida Ki Dukuh Sakti. Hal tersebut terlihat dari antosias masyarakat yang hendak melaksanakan upacara yajna didasari dengan selalu memohon berkat agar kegiatan upacara yang hendak dilaksanakan oleh masyarakat Desa Pakraman Gelogor dapat terlaksana dengan baik dan direstui oleh $I d a K i$ Dukuh Sakti. Dalam kutipan berikutnya juga dijelaskan tentang tindakan-tindakan masyarakat yang mencerminkan kepercayaannya terhadap teks mitos $I d a$ $K i$ Dukuh Sakti dalam hal yang berhubungan dengan niskala. Hal tersebut dapat dilihat pada kutipan berikut ini.

“...akéh krama irika nunas taksu. Sakadi taksu kesenian, lantas ring pejabat nunas 
taksu dumogi ngemolihang labda, lan mangda sekancan sajeroning pakaryan sané kegelitin olih krama irika mangdané maduwé jiwa utawi taksu, tiosan ring asapunika genah lan kawigunan Pura Gelar dados anggén nunas taksu utawi kesidian, nunas pengayoman niskala mangdané pariindik sané nénten becik tan mrasida ngranjing ring wewakon Desa Pakraman Gelogor prasida kabendung saking sakatah penjuru tan mresidayang ngeranjing mantuk wewidangan Desa Pakraman Gelogor, sumangdané sané marupa pengiwa nénten mewiguna."

Terjemahan :

"...banyak masyarakat di sana yang memohon taksu di Pura Gelar, seperti taksu kesenian (topeng, bondres), kemudian seorang pejabat memohon taksu untuk meraih kesuksesan, dan segala profesi yang digeluti oleh masyarakat disana memiliki jiwa (taksu). Selain itu, seperti dijelaskan di atas fungsi Pura Gelar selain sebagai tempat memohon taksu (kesidian), juga sebagai tempat memohon perlindungan niskala (benteng niskala) agar hal-hal negatif yang ingin memasuki wilayah Desa Pakraman Gelogor dapat dibendung dan segala hal negatif yang masuk ke areal Desa Pakraman Gelogor tidak dapat berfungsi."

Dari kutipan ini dapat disimpulkan bahwa selain sebagai tempat memohon kerahayuan dan kelancaran dalam upacara yajna pada Pura Gelar dan sebagai tempat untuk memohon taksu.

\section{(3) Musibah Yang Terjadi di Desa Pakraman Gelogor}

Musibah adalah suatu kejadian yang merugikan hidup kita yang terjadi di suatu tempat, yang menimbulkan rasa sedih yang mendalam, rasa was-was, takut, dan kerugian material. Dalam hal ini dapat diceritakan pada teks mitos Ida Ki Dukuh Sakti, pernah terjadi konflik sosial antar dua Desa Pakraman yaitu Desa Pakraman Gelogor dengan Desa Pakraman Silungan. Pada teks menceritakan bahwa konflik yang terjadi antara dua Desa Pakraman tersebut semata-mata mempertebal keyakinan masyarakat Desa Pakraman Gelogor terhadap perlindungan Ida Ki Dukuh Sakti dapat dilihat pada kutipan teks berikut.

“...Naenan dumun wénten silang pendapat krama Pakraman Gelogor sareng krama Desa Silungan, makacihna kekalih krama ring Desa Pakraman Gelogor sareng Desa Silungan pada tan purun ke suang-suang wawengkon sané wénten kabrebehan manggih indik punika raris para prajuru lan pemangku ring Desa Pakraman Gelogor nunas wantuan majeng Ida Ki Dukuh Sakti ring Pura Gelar mangda rerèncangan Idané tedun ngewantu krama yéning krama Silungan nyerang ring wewidangan Desa Pakraman Gelogor. Ritatkala rahina wengi wénten krama Silungan sané nyerang wawengkon Desa Gelogor, krama Silungan angob tur tengkejut sawiréh wilangan krama Desa Pakraman Gelogoré kirang langkung satus jiwa pinadosné dados ngenah akéhné siu diri sawiréh kawantu ring niskala olih Ida Ki Dukuh Sakti, krama wong samar lan reréncangan Idané. Ring pariindik punika, krama Desa Pakraman Gelogor kéwanten éling ngaturang bhakti ring Pura Gelar."

Terjemahan :

“...Dahulu pernah terjadi konflik antara krama Desa Pakraman Gelogor dengan krama Desa Silungan, yang menyebabkan suasana kedua daerah tersebut mencekam, tak hayal para prajuru dan pemangku di Desa Pakraman Gelogor memohon bantuan kepada Ida Ki Dukuh Sakti di Pura Gelar agar panjak wong samar dan rerencangan beliau dapat membantu krama jika di serang oleh krama desa Silungan. Ketika krama 
desa Silungan hendak menyerbu wilayah Gelogor, krama Silungan langsung heran dan panik karena dari jumlah penduduk Gelogor yang hanya kurang dari $100 \mathrm{KK}$ dilihat oleh krama Silungan berjumlah ribuan orang karena dibantu secara niskala oleh Ida Ki Dukuh Sakti serta panjak wong samar dan rerencangan beliau. Atas dasar kejadian itu, krama Desa Pakraman Gelogor tidak pernah lupa untuk selalu ingat sembahyang di Pura tersebut."

Pada kutipan di atas dijelaskan bahwa peran dari Ida Ki Dukuh Sakti bagi kesejahteraan masyarakat di Desa Pakraman Gelogor sangat penting, hal tersebut dapat dilihat dengan masih ingat dan bhaktinya masyarakat terhadap beliau yang ditunjukan dengan selalu ingatnya masyarakat untuk selalu beryajna terhadap beliau melalui tempat pemujaan beliau di Pura Gelar.

\section{3) Penutup}

Bagian penutup merupakan sebuah karya sastra yang kadang-kadang ditambahkan sebagai ikthisar, tetapi lebih sering sebagai pemikiran tambahan (Zaidan, 1994: 70). Menurut Kamus Besar Bahasa Indonesia (1999: 268) bagian penutup pada sebuah karya sastra yang fungsinya menyampaikan inti sari cerita atau menafsirkan maksud karya tersebut. Kutipan yang menunjukan hal tersebut dapat dilihat sebagai berikut.

“...sraddha krama ring Desa Pakraman Gelogor indik Ida Ki Dukuh Sakti punika kantun ajeg kalaksanain olih krama sareng sami. Sradha punika cirinyané krama ring Desa Pakraman Gelogor setata éling piodalan ring Pura Gelar."

Terjemahan :

“...kepercayaan masyarakat di Desa Pakraman Gelogor tentang Ida Ki Dukuh Sakti masih tetap terjaga, hal tersebut ditandai dengan selalu ingatnya masyarakat tatkala piodalan di Pura Gelar."
Kutipan tersebut merupakan bagian penutup dari teks mitos Ida Ki Dukuh Sakti. Bagian penutup dalam karya ini merupakan bagian akhir yang mengakhiri peristiwa induk atau inti cerita. Bagian penutup dalam teks mitos Ida Ki Dukuh Sakti berisi berupa nasehat spiritual dan kepercayaan-kepercayaan masyarakat setempat yang ditunjukan kepada para pembaca agar memahami fungsi dan nilai-nilai yang terdapat dalam teks agar dapat diterapkan dalam kehidupan sehari-hari.

\section{Fungsi Teks Mitos Ida Ki Dukuh Sakti}

Fungsi sastra dalam masyarakat sering masih lebih wajar dan langsung terbuka untuk penelitian ilmiah (Teeuw, 1984: 304). Luxemburg (1986: 94-95) menyebutkan bahwa fungsi sebuah teks adalah keseluruhan sifat-sifat yang bersama-sama menuju tujuan yang sama serta dampaknya. Fungsi yang terkandung dalam teks mitos Ida Ki Dukuh Sakti, yaitu fungsi sosial, fungsi sebagai keharmonisan unsur alam dan fungsi religius.

\section{1) Fungsi Sosial}

Fungsi sosial dalam teks mitos Ida Ki Dukuh Sakti di Pura Gelar ini terlihat pada saat adanya upacara yajna yang dilaksanakan oleh masyarakat Desa Pakraman Gelogor. Pada saat itu semua warga desa bergotong-royong untuk melaksanakan tugas sesuai kemampuan yang dimiliki. Kegiatan sosial ini dikenal oleh masyarakat setempat sebagai kegiatan yangh didasari hati yang tulus iklas. Kegiatan tersebut dikenal dengan istilah ngayah.

\section{2) Fungsi Sebagai Keharmonisan Unsur Alam}

Fungsi sebagai keharmonisan unsur alam dalam teks mitos $I d a K i$ 
Dukuh Sakti dapat dilihat dengan adanya mitos Ida Ki Dukuh Sakti yang berkembang di masyarakat Desa Pakraman Gelogor yang meyakini tentang kesakralan lingkungan di tempat tersebut menjadikan pemahaman masyarakat untuk selalu menjaga kelestarian alam di sekitar Pura Gelar pada khususnya dan di wilayah Desa Pakraman Gelogor pada umumnya. Hal ini menjaga prilaku-prilaku masyarakat untuk tidak semena-mena dalam tindakan terhadap lingkungan Pura tersebut. Tindakan tersebut juga berhimbas kepada alam atau lingkungan di Desa Pakraman Gelogor yang senantiasa selalu dijaga dan dipelihara oleh masyarakat karena mereka menyadari semua lingkungan alam memiliki jiwa atau roh yang harus disakralkan dan dijaga agar terciptanya lingkungan alam yang harmonis dan lestari.

\section{3) Fungsi Religius}

Fungsi religius yang terkandung di dalam mitos Ida Ki Dukuh Sakti terdapat tiga aspek fungsi yaitu 1. tattwa, 2. susila, dan 3. upacara. (1) Fungsi tattwanya memberi amanat bagi kepercayaan umat di Desa Pakraman Gelogor yang mengajarkan bahwa keberadaan dari Pura Gelar memupuk kepercayaan masyarakat bahwa manusia tidak akan pernah lepas hubungannya dengan Tuhan. (2) Fungsi susilanya ialah masyarakat setempat meyakini keberadaan Pura Gelar dijadikan sebagai sarana untuk memupuk rasa kepercayaan masyarakat terhadap eksistensi $I d a K i$ Dukuh Sakti dan senantiasa dijadikan pemicu hubungan timbal balik antara masyarakat dengan sraddhanya yaitu masyarakat selalu ingat dan bhakti kepada beliau dalam suatu kegiatan upacara yang hendak dilakukan oleh masyarakat agar selalu diberkati oleh beliau. (3) Fungsi upacaranya ialah kegiatan upacara pada Pura Gelar menjadi bukti bahwa masyarakat percaya dengan keberadaan Ida Ki Dukuh Sakti sebagai pengayom dan pelindung sekala niskala bagi masyarakat Desa Pakraman Gelogor.

Nilai

Nilai itu merupakan ajaran atau tuntutan kemanusiaan untuk kehidupan manusia yang memiliki kegunaan. Nilainilai yang terdapat pada teks mitos $I d a K i$ Dukuh Sakti ada dua yaitu nilai magis dan nilai kearifan lokal.

\section{1) Nilai Magis}

Nilai magis yang terkandung dalam teks mitos Ida Ki Dukuh Sakti di Pura Gelar ialah jika ada masyarakat yang masih berani sembarangan di areal Pura Gelar, masyarakat akan mendapatkan konsekwensinya berupa gangguan niskala dari rerencangan Ida Ki Dukuh Sakti dan wong samar.

\section{2) Nilai Kearifan Lokal}

Nilai kearifan lokal yang terkandung dalam teks mitos Ida Ki Dukuh Sakti di Pura Gelar ialah kepercayaan tersebut hanya dilakukan di Desa Pakraman Gelogor dari dahulu hingga sekarang. Kepercayaankepercayaan tersebut merupakan bukti bahwa nilai kearifan lokal yang terdapat di Desa Pakraman Gelogor masih sangat kental dan lestari. Kepercayaan masyarakat untuk memohon keselamatan dan perlindungan dari Ida Ki Dukuh Sakti menunjukan peran dari Pura Gelar sebagai tempat pemujaan Ida Ki Dukuh sakti sangat sentral atau penting bagi keberadaan Desa Pakraman Gelogor. Keyakinan itu membuat masyarakat tidak akan pernah lepas dari kegiatan pemujaan yang berlangsung di Pura Gelar, hal tersebut ditunjukan dengan tindakan masyarakat yang selalu melaksanakan yajna yang ditunjukan di pura tersebut untuk memohon kerahayuan dalam 
segala kegiatan yajna yang dilakukan masyarakat maupun permasalah sosial yang terjadi di Desa Pakraman Gelogor bilamana tidak dapat diselesaikan dengan sekala atau penyelesaian secara nyata dan riil.

\section{Simpulan}

Teks mitos Ida Ki Dukuh Sakti di Pura Gelar Desa Pakraman Gelogor dibangun dengan struktur isi. Struktur isi dibagi menjadi tiga bagian utama, ialah 1. Bagian pembukaan menjelaskan tokoh utama yaitu sosok Ida Ki Dukuh sakti , 2. Bagian isi dibagi menjadi tiga unsur yaitu upacara, sraddha, dan musibah yang terjadi di Desa Pakraman Gelogor, dan 3. bagian penutup mejelaskan tentang nasehat spiritual atau kepercayaankepercayaan masyarakat setempat yang ditunjukan kepada para pembaca. Fungsi teks mitos Ida Ki Dukuh Sakti di Pura Gelar Desa Pakraman Gelogor dalam kehidupan masyarakat berkaitan dengan fungsi sosial, fungsi sebagai keharmonisan unsur alam, dan fungsi religius. Nilai yang terkandung di dalam teks mitos Ida Ki Dukuh Sakti ada dua yaitu nilai magis dan nilai kearifan lokal.

\section{Daftar Pustaka}

Arwati, Ni Made Sri. 2010. Dharma Tula Dewa Yadnya. Denpasar: Upada Sastra.

Depdikbud , 1999. Kamus Besar Bahasa Indonesia. Jakarta: Balai Pustaka, Depdikbud.

Ghazali, Adeng Muchtar. 2011. Antropologi (Agama Upaya Memahami Keragaman Kepercayaan, Keyakinan, dan Agama). Bandung: Alfabeta.

Hutomo, Saripan Sadi. 1991. Mutiara Yang Terlupakan: Pengantar Studi Lisan. Jatim: Hiski.
Luxemburg, Jan Van, Mieke Bal, dan Willem G. Weststeijn. 1986. Pengantar Ilmu Sastra (terj.Dick Hartoko).Jakarta: PT. Gramedia.

Ratna, Nyoman Kutha. 2009. Stilistika: "Kajian Puitika Bahasa, Sastra, dan Budaya”. Yogyakarta: Pustaka Pelajar.

Sudjiman, Panuti. 1984. Memahami Cerita Rekaan. Jakarta: Gramedia Pustaka Utama.

Suhardana, Drs. K.M. 2008. Dasar-dasar Kesulinggihan Suatu Pengantar Bagi Sisya Calon Sulinggih. Surabaya: Paramita.

Teeuw, A. 1984. Sastra dan Ilmu Sastra. Pengantar Teori Sastra. Jakarta: Pustaka Jaya.

Triyono, Adi. 1994. "Langkah-langkah Penyusunan Rancangan Penelitian Sastra". Dalam Teori Penelitian Sastra Oleh Staf Pengajar UGM dkk. Yogyakarta: Masyarakat Poelika Indonesia IKIP Muhammadiyah Yogyakarta.

Zaidan, Abdul Rozak, dkk. 1994. Kamus Istilah Sastra. Jakarta: Balai Pustaka. 